\title{
Effect of thunderstorms and airborne grass pollen on the incidence of acute asthma in England, 1990-94
}

\author{
Roger Newson, David Strachan, Ewan Archibald, Jean Emberlin, Paul Hardaker, \\ Chris Collier*
}

\begin{abstract}
Background - Thunderstorms and prior grass pollen counts were investigated as predictors of daily hospital admissions for asthma in England. This study was motivated by reports in the literature of spectacular asthma epidemics associated with thunderstorms, particularly in the grass pollen season.

Methods - Asthma admissions for two age groups (0-14 years and 15 and over) were measured using the Hospital Episodes System (HES) in the 14 regional health authorities (RHAs) in England. Thunderstorms were measured daily in each RHA using densities of sferics (lightning flashes). Relative asthma excesses for moderate positive and exceptionally high sferic densities, with or without previous high grass pollen counts, were measured using log linear autoregression - allowing for weekly, seasonal, and longer term background variation - and pooled over RHAs by calculating geometric means.

Results - Relative risks from all RHAs were pooled to form geometric means. Exceptional sferic densities were associated with a relative excess risk of around $25 \%$ in both age groups. Moderate sferic densities were associated with a smaller excess, statistically significant in the two age groups taken together. In five RHAs in which grass pollen counts were available, high pollen counts for the previous five days were associated with an amplification of the excess associated with thunderstorms.
\end{abstract}

Conclusion - Very large sferic densities are associated with moderate rises in hospital admissions for acute asthma. However, typical thunderstorm days are not associated with spectacular asthma epidemics of the scale previously reported in the literature. Thunderstorm-associated excesses are amplified after a run of high pollen counts.

(Thorax 1997;52:680-685)

Keywords: acute asthma, thunderstorms, grass pollen.

Institute of Environmental

Systems, University of

Salford, UK.

Correspondence to:

Dr D Strachan.

Received 27 September 1996

Returned to authors

6 January 1997

Revised version received

10 March 1997

Accepted for publication

13 March 1997

There have been several published reports in the literature of epidemics of acute asthma which took place at, or immediately after, the time of a nearby thunderstorm. ${ }^{1-5}$ A spectacular example took place on the night of 24-25 June 1994 when a thunderstorm in south east
England was followed closely by a tenfold increase in attendance of patients at hospital casualty departments due to acute asthma attacks. $^{23}$ Mechanisms have been proposed whereby thunderstorms might cause acute asthma attacks. In the case of the June 1994 epidemic, it was found that an exceptionally high grass pollen count had been recorded in London two days previously. ${ }^{3}$ It has been proposed that the humidity preceding a thunderstorm, or rainfall during a thunderstorm, might lead to rupture of pollen grains releasing submicroscopic starch granules which are then broadcast by the rapid air movement associated with the thunderstorm. ${ }^{6}$ These fragments carry allergens such as $\operatorname{Lol} p \mathrm{IX}^{7}$ and were proposed as the cause of thunderstorm-associated asthma epidemics in Melbourne. ${ }^{4}$

Clearly, not all thunderstorms are associated with asthma epidemics on the scale experienced in June 1994. Therefore, even if there is a causal link between thunderstorms and asthma, there must be some other factors which interact with the thunderstorms that would have to be taken into account in building any early warning system for asthma epidemics. These factors might be aeroallergens such as those from grass pollen.

In this report we quantify the rise in the incidence of asthma which typically follows a thunderstorm in England and investigate whether this rise is greater after periods of high levels of grass pollen.

\section{Methods}

ACUTE ASTHMA MEASUREMENT

Daily counts of asthma admissions for each National Health Service regional health authority (RHA) were taken from the Hospital Episodes System (HES). For each RHA and day (midnight to midnight) asthma admissions were categorised by the age of the patient into two groups, one for those aged up to 14 and one for those aged 15 and above. The time series for the two age groups show a markedly different seasonal pattern with the younger group having large seasonal peaks and troughs which coincide with the beginnings and ends, respectively, of school terms. ${ }^{8}$

In principle, data were available for all days

from the beginning of January 1990 (when sferic data became available) to the end of March 1994. It was decided to exclude data from the latter month to allow for time taken for the system to $\log$ an episode, so the time 
series for each RHA was considered to end on 28 February 1994 (inclusively). Moreover, inspection of daily admissions for all respiratory disease (not shown) revealed vast local variation in time taken for the HES system to become reliable in reporting admissions, both between RHAs and between district health authorities (DHAs) within RHAs. Many of the DHAs had gaps in the record which appeared to be attributable, at least in part, to upheaval caused by the reorganisation of DHAs within RHAs. To avoid complications caused by such incomplete records, it was decided to start the time series for each RHA at a date by which the gaps for each DHA in that RHA appeared small enough to be treated as part of the autocorrelated random error. In the case of the North Western RHA, two small DHAs (Oldham District and Chorley and South Ribble District) were excluded from the analysis altogether because their incomplete data seemed to persist into the 1990 s while the remainder of that RHA seemed to produce complete data from 1987 (when the system was officially activated).

\section{THUNDERSTORM MEASUREMENT}

Information on thunderstorm activity was derived from records of sferics (lightning flashes) provided by the Meteorological Office using the operational system described by Lee. ${ }^{9} \mathrm{~A}$ sferic is the electromagnetic signal emitted during lightning discharge and is generally strongest at frequencies around the $10-16 \mathrm{kHz}$ band. Using geographically separate sensors operating at these frequencies it is possible to identify the timing and location of each lightning flash remotely by comparing the differences between arrival times at three or more different sensors. This method for identifying thunderstorms has a number of advantages over reliance on the records of ground based observers as it provides much greater spatial ${ }^{10}$ and temporal accuracy, more consistent data, and worldwide coverage. Moreover, by recording the amount of lightning produced at a particular time and place it also gives a quantitative measure of the vigour of convective activity within the storm. The amount of lightning produced by an individual storm can indicate the strength of convection and, hence, other characteristics such as the amount of precipitation or the strength of the downdraught and associated gust front. It is thus possible to attempt to discard weak and isolated thunderstorm events which might not be expected to have a measurable impact on asthma admissions.

Sferics data covering the whole of England were available, nearly continuously, from the beginning of 1990. Each sferic was localised to a day and a RHA to derive a daily count of the number of sferics originating in the area covered by each RHA, and each count was divided by the area of the RHA to give a sferics density measured in sferics per 100 square kilometres per day $\left(\mathrm{Sf} / 100 \mathrm{~km}^{2} /\right.$ day). To maintain consistency with standard climatological measurements, a day was defined to begin at 09.00 hours GMT and to end at 09.00 hours GMT on the following day. For statistical analysis each sferic density was matched to the asthma admissions data for the midnight-to-midnight date on which the corresponding sferic count ended, so that the sferic densities were lagged by 15 hours relative to the asthma counts. An alternative matching policy was to match each sferic density to the asthma admissions data for the date on which the sferics count began so that the sferic densities were lagged by -9 hours. The former match was expected to be the best for predictive purposes because the more vigorous thunderstorms tend to develop during the late afternoon and evening, and may have a greater impact on hospital admissions on the following day than on the current day as time is required for asthma to develop and for patients to present. However, the latter match was also considered because of the possibility that an afternoon thunderstorm might cause a wave of early evening asthma admissions.

POLLEN COUNTS

Pollen data were collected from various sites of the European Aeroallergen Network UK by the Pollen Research Unit. These sites monitor concentrations of airborne pollen using quality controlled standard techniques with volumetric traps. Daily mean grass pollen counts, measured in grains per cubic metre of air sampled per day $\left(\mathrm{Gr} / \mathrm{m}^{3} /\right.$ day), were used with days deemed to begin and end at 09.00 hours GMT for consistency with the meteorological data. Sferics and hospital admissions for the four Thames regions (North West, North East, South West and South East) were matched to pollen counts from London, whereas those from the Trent region were matched to pollen counts from Derby. At some stations pollen counts are not taken during the winter months and, occasionally, there are breaks in the records due to instrument failure and other problems. To make the time series as nearly complete as possible, missing counts in months from October to February were treated as zeros, as were missing counts immediately preceded by zero counts. Pollen counts were entered into the analysis as five day moving averages so that the sferic results for a $09.00-09.00$ day were matched with the mean of the pollen counts for that day and the previous four days. This strategy was based on the hypothesis that asthma attacks may be caused by rainfall disrupting, by osmotic shock, the pollen released over the previous few days, releasing starch granules. ${ }^{6}$

DATA ANALYSIS

The statistical method used was a log linear autoregression model for time series of counts used by Schwartz et $a l^{11}$ and originating as a variation of one introduced by Zeger. ${ }^{12}$ It is described in a statistical appendix at the end of the paper. Estimation of model parameters was carried out using a SAS program, available from the authors on request, which uses the 
Table 1 Observation periods, sferics density, and daily asthma admissions for the 14 RHAs in England

\begin{tabular}{|c|c|c|c|c|c|c|c|c|c|c|}
\hline \multirow{3}{*}{$\begin{array}{l}\text { RHA } \\
\text { code }\end{array}$} & \multirow[t]{3}{*}{ RHA name } & \multirow[t]{3}{*}{ First day* } & \multirow{3}{*}{$\begin{array}{l}\text { Total no. } \\
\text { of days }\end{array}$} & \multicolumn{3}{|c|}{$\begin{array}{l}\text { Sferic density group } \\
\left(\mathrm{Sf} / 100 \mathrm{~km}^{2} / \text { day }\right)\end{array}$} & \multicolumn{4}{|c|}{ Daily asthma admissions } \\
\hline & & & & & & & \multicolumn{2}{|c|}{ Ages $0-14$} & \multicolumn{2}{|c|}{ Ages $15+$} \\
\hline & & & & $\begin{array}{l}\text { Zero } \\
(0)\end{array}$ & $\begin{array}{l}\text { Low } \\
(<1)\end{array}$ & $\begin{array}{l}\text { High } \\
(\geq 1)\end{array}$ & Mean & $\operatorname{Max}$ & Mean & $\operatorname{Max}$ \\
\hline A & Northern & 1 April 1990 & 1430 & 1334 & 95 & 1 & 7.7 & 43 & 6.7 & 24 \\
\hline B & Yorkshire & 1 April 1992 & 699 & 635 & 62 & 2 & 9.4 & 44 & 8.4 & 20 \\
\hline $\mathrm{C}$ & Trent & $1 \mathrm{Jan} 1990$ & 1520 & 1354 & 157 & 9 & 10.3 & 45 & 10.9 & 28 \\
\hline $\mathrm{D}$ & East Anglian & 1 Jan 1990 & 1520 & 1357 & 157 & 6 & 3.6 & 21 & 4.0 & 14 \\
\hline $\mathrm{E}$ & NW Thames & 1 Appril 1990 & 1430 & 1315 & 107 & 8 & 9.6 & 45 & 7.2 & 24 \\
\hline $\mathrm{F}$ & NE Thames & 1 Jan 1990 & 1520 & 1421 & 92 & 7 & 10.9 & 50 & 9.3 & 34 \\
\hline G & SE Thames & 1 Jan 1990 & 1520 & 1383 & 128 & 9 & 9.0 & 38 & 8.0 & 25 \\
\hline $\mathrm{H}$ & SW Thames & 1 Jan 1990 & 1520 & 1376 & 134 & 10 & 6.4 & 32 & 4.9 & 18 \\
\hline $\mathrm{J}$ & Wessex & 1 Jan 1990 & 1520 & 1380 & 136 & 4 & 5.5 & 25 & 5.9 & 18 \\
\hline $\mathrm{K}$ & Oxford & 1 Jan 1990 & 1520 & 1402 & 110 & 8 & 5.5 & 24 & 4.0 & 15 \\
\hline $\mathrm{L}$ & South Western & 1 Jan 1990 & 1520 & 1326 & 192 & 2 & 6.3 & 31 & 6.7 & 19 \\
\hline$M$ & West Midlands & 1 April 1990 & 1430 & 1294 & 127 & 9 & 14.0 & 66 & 11.9 & 37 \\
\hline $\mathrm{N}$ & Mersey & $1 \operatorname{Jan} 1990$ & 1520 & 1434 & 84 & 2 & 6.9 & 28 & 7.0 & 22 \\
\hline $\mathrm{P}$ & North Western & 1 Jan 1990 & 1520 & 1427 & 89 & 4 & 14.1 & 53 & 11.2 & 30 \\
\hline
\end{tabular}

* Last day is 28 February 1994 in all regions.

Table 2 Relative risks associated with low and high positive sferic density compared with zero sferic density given as estimates, with 95\% confidence limits, of geometric mean over all RHAs using a 15 hour lag

\begin{tabular}{llll}
\hline & Age group & \\
\cline { 2 - 4 } & $0-14$ & $15+$ & All ages* \\
\hline Low sferics $\left(<1 \mathrm{Sf} / 100 \mathrm{~km}^{2} /\right.$ day) & $1.00(0.98$ to 1.02$)$ & $1.05(1.03$ to 1.08$)$ & $1.03(1.01$ to 1.04$)$ \\
High sferics $\left(\geq 1 \mathrm{Sf} / 100 \mathrm{~km}^{2} /\right.$ day) & $1.25(1.11$ to 1.39$)$ & $1.26(1.12$ to 1.41$)$ & $1.25(1.15$ to 1.36$)$ \\
\hline * Geometric mean relative risk over the two age groups.
\end{tabular}

procedures GENMOD ${ }^{13}$ and NLIN $^{14}$ of the SAS/STAT system. A model was fitted to the series of asthma admission counts for each of the two age groups in each of the 14 RHAs in England, and contained eight lag terms, together with the following classes of time dependent $x$ variates:

(1) A dummy variate indicating whether or not the day in question was a public holiday.

(2) Dummy variates for each day of the week (other than Sunday) indicating whether or not the day in question was a non-public holiday weekday of the appropriate kind. This modelled a weekly cycle.

(3) Fourier sine and cosine terms for the season of the year. These were defined for frequencies from one to 12 cycles per year.

(4) Terms for a quadratic spline with regular semi-annual knots at 1 March and $1 \mathrm{Sep}-$ tember. This modelled long term trends with some provision for season-year interactions.

(5) For some RHAs (North West Thames, South West Thames and Wessex) an additional dummy variate was included, taking values of 0 before 1 April 1993 and 1 afterwards. This was done because, on that date, there was a boundary change involving redistribution of territory amongst those three regions. The parameter for this dummy variate is interpreted as the log of the ratio of numbers of potential asthma patients after and before the redistribution.

(6) Two dummy variates for sferic densities, one for low positive densities (strictly below $1 \mathrm{Sf} / 100 \mathrm{~km}^{2} /$ day) and one for higher densities ( $1 \mathrm{Sf} / 100 \mathrm{~km}^{2} /$ day or more). The parameters for these dummy variates are the log relative risks associated with low and high positive sferic densities, respectively, compared with zero sferic density. (Relative risk, in this context, is the ratio of predicted counts in the presence and absence of a risk factor, other things being equal.)

For the five RHAs for which a fairly complete pollen count series could be obtained (the four Thames RHAs and Trent RHA), a further model was fitted to the data which contained all the above $x$ variates plus two extra dummy variates, one for high moving average pollen counts $\left(50 \mathrm{Gr} / \mathrm{m}^{3} /\right.$ day or more) in the presence of zero sferics density and one for high moving average pollen counts in the presence of nonzero sferics densities. The threshold of $50 \mathrm{Gr} /$ $\mathrm{m}^{3} /$ day was chosen because experience in clinical trials has shown that, at this concentration, most people who are allergic to grass pollen have symptoms. ${ }^{15}$

\section{Results}

The 14 RHAs in the study are listed in table 1 , by name and reference code, together with the first day of the time series analysed and the number of days in the series. (The last day is 28 February 1994 for all series.) The first day is either the first day for which sferic densities were available (1 January 1990) or the first day on which the particular RHA was considered to be returning reliable data, whichever is later (see Methods.) Table 1 also gives the variation in sferic densities between days, expressed as frequencies of three sferic density groups. Note that, for each RHA, about $90 \%$ of days were associated with zero sferic density on the previous day, and less than $1 \%$ of days were associated with a sferic density of $1 \mathrm{Sf} / 100 \mathrm{~km}^{2} /$ day or above, the remaining days having positive sferic densities below $1 \mathrm{Sf} / 100 \mathrm{~km}^{2} /$ day. Sferic density ranged to a maximum of 8.33.

The daily asthma admission counts for the two age groups in the 14 RHAs are also summarised in table 1 . Note that means vary from below 4 to above 14, but that the counts are 

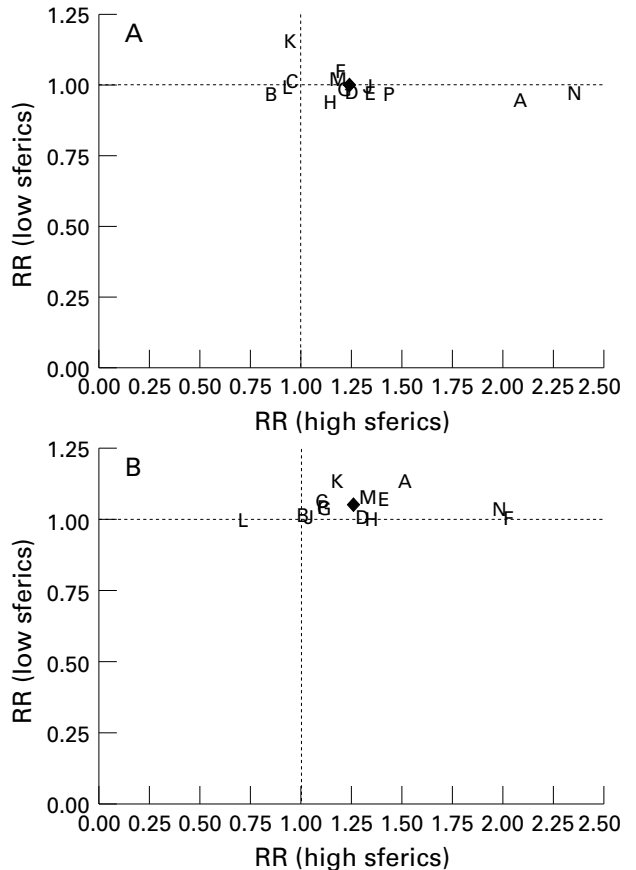

Figure 1 Scatter graphs about geometric means of the relative risks with low sferic densities for individual regional health authorities in $(A)$ patients aged $0-14$ years and $(B)$ those aged 15 and over.

everywhere highly variable, with the largest counts being more than twice the mean in every combination of RHA and age group, and five times the mean in some combinations.

Table 2 gives the geometric mean relative risks (over all RHAs) associated with high and low sferic densities (using a 15 hour lag) with upper and lower approximate $95 \%$ confidence limits. The scatter about the geometric means of the relative risks for individual RHAs is

Table 3 Numbers of high five day average pollen counts ( $\geq 50 \mathrm{Gr} / \mathrm{m}^{3} /$ day) associated with zero, low, and high sferics density

\begin{tabular}{llllll}
\hline $\begin{array}{l}\text { RHA } \\
\text { code }\end{array}$ & RHA name & \multicolumn{4}{c}{ Grass pollen counts (5 day average) } \\
\cline { 3 - 5 } & & Valid & $\begin{array}{l}\text { Zero } \\
\text { sferics }\end{array}$ & $\begin{array}{l}\text { Low } \\
\text { sferics }\end{array}$ & $\begin{array}{l}\text { High } \\
\text { sferics }\end{array}$ \\
\hline C & Trent & 1520 & 92 & 17 & 2 \\
E & NW Thames & 1402 & 65 & 12 & 2 \\
F & NE Thames & 1492 & 69 & 9 & 1 \\
G & SE Thames & 1492 & 69 & 8 & 2 \\
H & SW Thames & 1492 & 71 & 6 & 2 \\
Total & & 7398 & 366 & 52 & 9 \\
\hline
\end{tabular}

Table 4 Relative risks associated with low and high positive sferic density, and high pollen averages with and without sferics given as estimates, with 95\% confidence limits, of geometric means over regions with pollen series

\begin{tabular}{|c|c|c|c|}
\hline & \multicolumn{3}{|l|}{ Age group } \\
\hline & $0-14$ & $15+$ & All ages* \\
\hline \multicolumn{4}{|l|}{ Positive sferic group: $^{\mathrm{a}}$} \\
\hline Low $\left(<1 \mathrm{Sf} / 100 \mathrm{~km}^{2} /\right.$ day $)$ & $0.98(0.95$ to 1.02$)$ & $1.03(0.99$ to 1.07$)$ & $1.00(0.98$ to 1.03$)$ \\
\hline High ( $\geq 1 \mathrm{Sf} / 100 \mathrm{~km}^{2} /$ day $)$ & $1.13(1.02$ to 1.26$)$ & $1.28(1.15$ to 1.43$)$ & $1.21(1.11$ to 1.30$)$ \\
\hline \multicolumn{4}{|c|}{ High pollen count $\left(\geq 50 \mathrm{Gr} / \mathrm{m}^{3} /\right.$ day $):^{\mathrm{b}}$} \\
\hline Without sferics & $1.00(0.94$ to 1.07$)$ & $1.06(0.99$ to 1.13$)$ & $1.03(0.98$ to 1.08$)$ \\
\hline With sferics & $1.16(1.04$ to 1.31$)$ & $1.47(1.32$ to 1.64$)$ & $1.31(1.21$ to 1.42$)$ \\
\hline Ratio (with/without sferics) & $1.16(1.03$ to 1.31$)$ & 1.39 (1.24 to 1.56$)$ & 1.27 (1.17 to 1.38$)$ \\
\hline
\end{tabular}

${ }^{\text {a }}$ Compared with zero sferics.

${ }^{b}$ Compared with zero/low pollen count $\left(<50 \mathrm{Gr} / \mathrm{m}^{2} /\right.$ day $)$.

* Geometric mean relative risk over the two age groups. displayed graphically, without confidence limits, in fig 1 . It can be seen that, for both age groups, the estimated relative risks associated with high sferic densities varied considerably between RHAs. This is not surprising, given that each one compares a number of thunderstorm days between one and 10 with the majority of days which have zero sferic densities (see table 1). However, in both age groups most RHAs had a relative risk greater than one, and the geometric mean corresponds to a relative excess risk of roughly $25 \%$, with $95 \%$ confidence limits from $10 \%$ to $40 \%$. The relative risks associated with low sferic densities were less variable and typically were close to one. However, the relative risk for those aged 15 and above tended to be greater than one, so the geometric mean for both age groups in all RHAs corresponds to a significantly positive relative excess risk of $1-4 \%$.

It was thought possible (but not likely) that sferics lagged by -9 hours might predict asthma admissions better than sferics lagged by 15 hours (see Methods). Accordingly, the above analysis was repeated substituting a -9 hour lag for a 15 hour lag (not shown). However, in the case of high sferics the -9 hour confidence intervals included the "null value" of one for both age groups. It was concluded that the 15 hour lag predicted asthma admissions better than the -9 hour lag, and the former lag was therefore used in all subsequent analyses.

Table 3 gives the numbers of days with valid five day average pollen counts, and the numbers of those days on which this average was high (at least $50 \mathrm{Gr} / \mathrm{m}^{3} /$ day) with zero, low, and high sferic densities for the five RHAs for which a fairly complete series of pollen counts was available. The number of valid pollen averages is the same as the total number of days minus the number of missing pollen averages (none in the Derby series, 28 in the London series). The number of high pollen averages unaccompanied by sferics is typically around 5\% of the total, whereas the number of high pollen averages accompanied by a positive sferics density (however small) is typically around $1 \%$, of which only one or two per RHA precede a high sferics density.

Table 4 summarises (using geometric means over the four Thames regions and the Trent region) the relative risks associated with low and high positive sferic densities and with high pollen averages in the presence and absence of sferics. The ratio of high pollen relative risk with sferics to high pollen relative risk without sferics is given to measure the interaction between pollen counts and sferic densities, and is significantly greater than one in both age groups. (In the two age groups pooled together the interaction is significant at a level of $\mathrm{p} \leq 0.0001$.) The scatter around the geometric means of high pollen relative risks for the five individual RHAs is displayed in fig 2 .

The results shown in table 4 and fig 2 indicate that sferics (at least at high density) predict increases in asthma attacks even after zero, low, or moderate pollen averages, but the effect is even greater (and probably manifest at a lower 

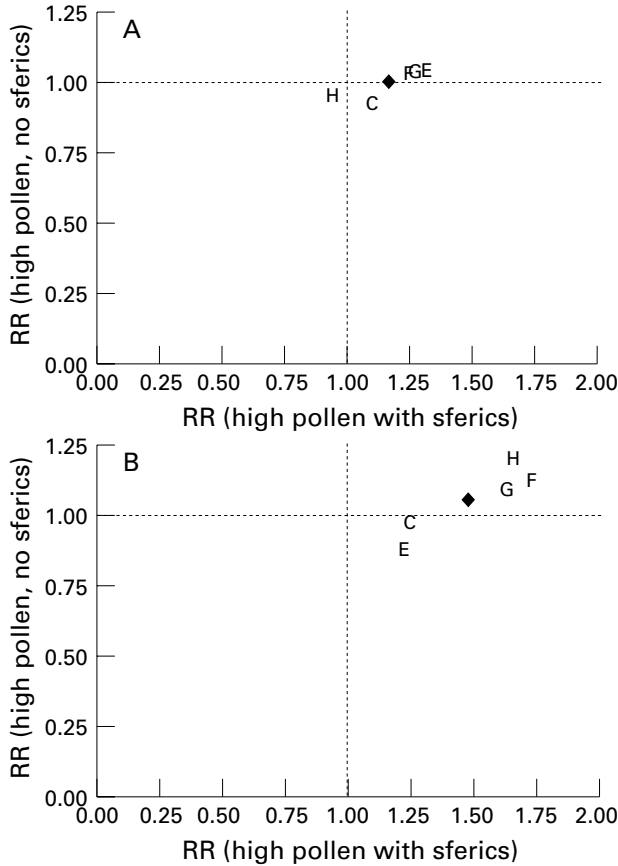

Figure 2 Scatter graphs about geometric means of the relative risks with high pollen and zero sferic densities for individual regional health authorities in $(A)$ patients aged 0-14 years and (B) those aged 15 and over.

density) after high pollen averages. This amplifying effect seems to be greater in adults than in children. The effect of high pollen averages in the presence of thunderstorms is significantly greater than the effect of high pollen counts in the absence of thunderstorms, which is too small to be measured.

\section{Discussion}

The public health questions asked by this project concern the advisability of an early warning system for hospitals based on a forecast of thunderstorms. There seems to be a gradient of risk between zero sferic days and high sferic days, with low sferic days having an intermediate risk. High sferic days, as defined in this report, account for less than $1 \%$ of the total number of days in all RHAs (table 1). The statistical methods used in this report are sufficiently sensitive to detect an increase in acute asthma associated with such a small number of days if the results are pooled over the 14 RHAs. However, they are also sufficiently specific to be able to rule out the possibility that a typical thunderstorm will be associated with a rise of $50 \%$, or worse, in hospital admissions with acute asthma. From table 1 it appears that a large RHA might expect 10 cases of asthma per day from each age group, totalling 20. A large front of thunderstorms sweeping over that RHA would typically cause 2.5 extra cases in each age group, giving an extra five cases in the whole RHA. An increase in admissions of this order, even if it is concentrated in one hospital or health district, is hardly likely to cause hospitals to run out of inhalers or other resources as was reported for London hospitals during the 1994 epidemic. $^{3}$

Not surprisingly, typical thunderstorms alone do not seem to cause spectacular asthma epidemics, so any worthwhile early warning system would presumably require the specification of other predictors. A possible cofactor in the case of the 1994 London epidemic was a six year record pollen count two days previously. ${ }^{3}$ This report confirms that a high five day moving grass pollen average is associated with an amplified excess of asthma admissions following a thunderstorm on the fifth day. A thunderstorm in the presence of a high pollen count is associated with a $16 \%$ excess of asthma admissions in children and a nearly $50 \%$ excess in adults compared with a thunderstorm of the same size and a moderate, low, or zero pollen average (table 4). Assuming that high pollen averages amplify the high sferic effect as much as they amplify the low sferic effect, this implies an excess of $45 \%$ in children and a near doubling in adults for a high sferic, high pollen day compared with a zero sferic, low pollen day. It is not feasible to test this assumption here because there are so few high sferic, high pollen days (table 3). However, although a tenfold increase is still atypical, the role of pollen as a cofactor is large enough to be measured.

The observed modest effects may be partly caused by variation within RHA of the pollen dosage, so that the London five day average is not representative of the whole area of the four Thames RHAs, although it might be representative of London. Similarly, regional sferics density might not detect severe, highly localised thunderstorms. In these cases, combined sferic data and pollen averages might possibly predict asthma epidemics better in a compact, densely populated area such as London than they do in the four Thames RHAs. On the other hand, we do not know how well a five day moving average of airborne pollen measures the "reservoir" of settled pollen awaiting osmotic shock on the fifth day.

A question naturally arises as to whether the observed link between pollen, thunderstorms, and asthma might really be caused by mechanisms less direct than the one hypothesised here. Proposed trigger factors include fungal spores $^{5}$ and pollutants such as particulate matter $\left(\mathrm{PM}_{10}\right)$, ozone, and nitrogen oxides. ${ }^{16}$ In the case of air pollutants, at least, spectacular nitrogen dioxide episodes do not necessarily lead to asthma epidemics, and the 1994 London asthma episode was not associated with high levels of $\mathrm{PM}_{10}$, nitrogen dioxide, or ozone. $^{16}$

The forecasting approach of this paper is based on a comparison of typical high sferic and/or high pollen days with zero sferic, low pollen days. The results do not rule out the possibility that some high sferic and/or high pollen days are atypical, either by having extremely high sferic densities and pollen simultaneously or in other respects, and therefore produce large asthma epidemics. A way of investigating this possibility, which we have explored elsewhere, is to isolate spectacular 
asthma epidemic days and to compare them with control days one week before and after, and with other non-epidemic days, with regard to available risk indicators.

\section{Appendix: Log linear autoregression}

In a log linear regression model, if the count on day $t$ is denoted $y_{t}$, then the conditional mean and variance of the count for the $t$ th day, given the observed values of a set of time dependent $x$ variates, are given by:

$$
\begin{gathered}
\text { mean }\left(y_{t}\right)=\mu_{t}=\exp \left(\sum_{j=1}^{p} x_{t} \beta_{j}\right) \\
\text { variance }\left(y_{t}\right)=\Phi \mu_{t}
\end{gathered}
$$

where $p$ is the number of $x$ variates, $x_{t j}$ is the value of the $j$ th $x$ variate on day $t, \beta_{j}$ is the corresponding log linear regression coefficient, the function $\exp (\mathrm{z})=\mathrm{e}^{\mathrm{z}}$ is the exponential function, and $\Phi$ is a proportionality constant whereby the variance is proportional to the mean. Each $\beta_{j}$ therefore measures the multiplicative effect, or relative risk, associated with one additional unit of the $j$ th $x$ variate. If this $x$ variate is a "dummy" for a "yes-no" binary variate such as presence or absence of a thunderstorm, taking on values of 1 for "yes" and 0 for "no", then $\exp \left(\beta_{j}\right)$ is the relative risk associated with a "yes" answer. The quantities

$$
r_{t}=y_{t}-\mu_{t}
$$

denoted the residuals, have a mean value of zero, and the same variance as the corresponding count $y_{t}$. Under an ordinary log linear regression model these $r_{t}$ values would be mutually uncorrelated. Under the log linear autoregression model used here the ordinary residuals $r_{t}$ are not uncorrelated, and the count $y_{t}$ can be forecast more accurately by taking into account the previous counts $y_{t-1}, \ldots, y_{t-q}$, where $q$ is a maximum lag. The forecast value of $y_{t}($ for $t>q)$ is

$$
\mu^{*}{ }_{t}=\mu_{t}+\sum_{j=1}^{q} \alpha_{j}\left(\sqrt{\frac{\mu_{t}}{\mu_{t-j}}}\right) r_{t-j}
$$

where the $\alpha_{j}$ are autocorrelation parameters. (The $\alpha_{j}$ are transformed to autoregression parameters by the factors $\sqrt{\mu_{t} / \mu_{t-j}}$, which are ratios of standard deviations.) The autoregressive residuals, given by the equation

$$
r_{t}^{*}=y_{t}-\mu^{*}{ }_{t}=r_{t}-\sum_{j=1}^{q} \alpha_{j}\left(\sqrt{\frac{\mu_{t}}{\mu_{t-j}}}\right) r_{t-j}
$$

are assumed to be uncorrelated, with variances equal to those of the corresponding regressive residuals. The parameters $\beta_{j}$ and $\alpha_{j}$ were estimated, with standard errors, by a quasilikelihood method. ${ }^{17}$ Log linear confidence intervals for relative risks were calculated in the usual manner from estimates and standard errors of the $\beta$ parameters. (For instance, an estimate for a relative risk, with approximate $95 \%$ confidence limits, is given by

$$
\exp [\hat{\beta} \pm 2 \operatorname{SE}(\hat{\beta})]
$$

where $\beta$ is the estimated log relative risk and $\mathrm{SE}(\hat{\beta})$ is the corresponding standard error.)

To pool (or "meta-analyse") the relative risks for $m$ distinct sets of data, a model was fitted separately to each set of data and the geometric mean relative risk was estimated by estimating the mean log relative risk, with its standard error, as

$$
\begin{gathered}
\hat{\beta}_{\mathrm{pool}}=m^{-1} \sum_{i=1}^{m} \hat{\beta}_{i} \\
\mathrm{SE}\left(\hat{\beta}_{\mathrm{pool}}\right)=\sqrt{m^{-2} \sum_{i=1}^{m} \mathrm{SE}\left(\hat{\beta}_{i}\right)^{2}}
\end{gathered}
$$

(where $\hat{\beta}$ is the $\log$ relative risk for the $i$ th data set and $\hat{\beta}_{\text {pool }}$ is the mean log relative risk), and by inserting the pooled estimate and standard error into equation (5) to calculate a confidence interval for the geometric mean.

The authors would like to thank the National Asthma Campaign for financial support and the pollen monitoring sites of the European Aeroallergen Network UK for allowing the grass pollen data to be used in this research.

1 Bauman A. Asthma associated with thunderstorms. BMF 1996;312:590-1.

2 Celenza A, Fothergill J, Kupek E, Shaw RJ. Thunderstorm associated asthma: a detailed analysis of environmental associated asthma: a detailed
factors. BMf 1996;312:604-7.

3 Davidson AC, Emberlin J, Cook AD, Venables KM, Thames Regions Accident and Emergency Trainers Association. A major outbreak of asthma associated with a thunderstorm experience of accident and emergency patients' characteristics. BMF 1996;312:601-4

4 Bellomo R, Gigliotti P, Treloar A, Holmes P, Suphioglu C, Singh MB, et al. Two consecutive thunderstorm associated epidemics of asthma in the city of Melbourne. Med $\mathcal{F}$ Aust 1992;156:834-7.

5 Packe GE, Ayres JG. Asthma outbreak during a thunderstorm. Lancet 1985;ii:199-204.

6 Knox RB. Grass pollen, thunderstorms and asthma. Clin Exp Allergy 1993;23:354-9.

7 Suphioglu C, Singh MB, Taylor P, Bellomo R, Holmes P, Puy R, et al. Mechanism of grass-pollen-induced asthma. Lancet 1992;339:569-72.

8 Storr J, Lenney W. School holidays and admissions with asthma. Arch Dis Child 1989;64:103-7.

9 Lee ACL. An operational system for the remote location of lightning flashes using a VLF arrival time difference of lightning flashes using a VLF arrival tim

10 Lee ACL. Ground truth confirmation and theoretical limits of an experimental VLF arrival time difference lightning flash locating system. Q f R Met Soc 1989;115:1147-66.

11 Schwartz J, Spix C, Touloumi G, Bacharova L, Barumandzadeh T, Le Tertre A, et al. Methodological issues in studies of air pollution and daily counts of deaths or hospital admissions. F Epidemiol Community Health 1996 50(Suppl 1):S3-11.

12 Zeger SL. A regression model for time series of counts. Biometrika 1988;75:621-9.

13 SAS Institute Inc. SAS/STAT Software: the GENMOD Procedure. SAS Technical Report P-243, Release 6.09. Cary, North Carolina: SAS Institute Inc, 1993:88 pp.

14 SAS Institute Inc. The NLIN Procedure. In: $S A S / S T A T$ User's Guide, Version 6, 4th ed, Volume 2. Cary, North Carolina: SAS Institute Inc, 1989:1136-94.

15 Davies RR, Smith LP. Forecasting the start and severity of the hayfever season. Clin Allergy 1973;3:263-7.

16 Anderson HR, Atkinson R, Limb ES, Strachan DP. Epidemic of asthma was not associated with episode of air pollution. BMF 1996;312:1606-7.

17 McCullagh P, Nelder JA. Generalized linear models. 2nd ed. London: Chapman and Hall, 1989:323-56. 